\title{
Updated distribution and species composition of the amphibians and reptiles along the Lower Danube, Bulgaria
}

\author{
Georgi Popgeorgiev ${ }^{\ddagger}$, Borislav Naumov§${ }^{\S}$, Yurii Kornilev $¥$, , , Vladislav Vergilov ${ }^{\ddagger}$, \\ Miroslav Slavchev $\ddagger$, , Simeon Lukanov§, Angel Dyugmedzhiev§, Andrey Stoyanov ${ }^{\dagger, \ddagger}$, \\ Dobrin Dobrevt,§, Nikolay Tzankovt,‡ \\ ‡ National Museum of Natural History-BAS, Sofia, Bulgaria \\ § Institute of Biodiversity and Ecosystem Research, Sofia, Bulgaria \\ | Department of Integrative Zoology, University of Vienna, Vienna, Austria \\ † Deceased author
}

Corresponding author: Yurii Kornilev (yukornilev@gmail.com)

Received: 14 Sep 2019 | Published: 16 Sep 2019

Citation: Popgeorgiev G, Naumov B, Kornilev Y, Vergilov V, Slavchev M, Lukanov S, Dyugmedzhiev A, Stoyanov A, Dobrev D, Tzankov N (2019) Updated distribution and species composition of the amphibians and reptiles along the Lower Danube, Bulgaria. ARPHA Conference Abstracts 2: e46571. https://doi.org/10.3897/aca.2.e46571

\section{Abstract}

In a recently published paper (Popgeorgiev et al. 2019), we compiled for the first time published and unpublished data on localities of the herpetofaunal species observed up to ca. $10 \mathrm{~km}$ south of the Bulgarian Danube River. Overall, we identified 687 published records belonging to 62 cells of the $10 \times 10 \mathrm{~km}$ MGRS grid. Another 1918 records with real coordinates of our unpublished data from the past ca. 13 years belong to 1269 cells of the $1 \times 1$ MGRS grid. As a result, 34 native species -15 amphibians (4 salamanders and 11 frogs) and 19 reptiles ( 1 turtle, 2 tortoises, 8 lizards and 8 snakes), and one invasive turtle, have been recorded; further species findings are unlikely. This study further identifies areas that are under-sampled and species such as Pelophylax lessonae that are cryptic. Our data are especially relevant concerning the high economic incentives to change the hydrology of the Danube, which will likely negatively impact the biodiversity along the river and its surrounding. 


\section{Keywords}

Amphibia, Reptilia, herpetofauna, species composition, river, conservation

\section{Presenting author}

Yurii Kornilev

\section{Presented at}

$\mathrm{V}^{\text {th }}$ International Congress on Biodiversity: „Taxonomy, Speciation and Euro-Mediterranean Biodiversity“

\section{References}

- $\quad$ Popgeorgiev G, Naumov B, Kornilev Y, Vergilov V, Slavchev M, Lukanov S, Dyugmegdzhiev A, Stoyanov A, Dobrev D, Tzankov N (2019) Diversity and Distribution of Amphibians and Reptiles in the Bulgarian Part of the Lower Danube. Biodiversity of the Bulgarian-Romanian section of the Lower Danube. [ISBN 978-1-5361-5664-5]. 